Cahiers $d u$ MONDE RUSSE

\section{Cahiers du monde russe}

Russie - Empire russe - Union soviétique et États indépendants

$52 / 4 \mid 2011$

Varia

\title{
Geneviève Piron, Léon Chestov, philosophe du déracinement
}

\author{
loulia Podoroga
}

\section{OpenEdition}

\section{Journals}

Édition électronique

URL : http://journals.openedition.org/monderusse/7678

DOI : $10.4000 /$ monderusse. 7678

ISSN : $1777-5388$

Éditeur

Éditions de l'EHESS

\section{Édition imprimée}

Date de publication : 20 décembre 2011

Pagination : 839-841

ISBN : 978-2-7132-2353-2

ISSN : $1252-6576$

Référence électronique

Ioulia Podoroga, "Geneviève Piron, Léon Chestov, philosophe du déracinement », Cahiers du monde russe [En ligne], 52/4 | 2011, mis en ligne le 03 décembre 2012, Consulté le 22 septembre 2020. URL http://journals.openedition.org/monderusse/7678; DOI : https://doi.org/10.4000/monderusse.7678

Ce document a été généré automatiquement le 22 septembre 2020

(c) École des hautes études en sciences sociales 


\title{
Geneviève Piron, Léon Chestov, philosophe du déracinement
}

\author{
loulia Podoroga
}

\section{RÉFÉRENCE}

Geneviève PIRON, Léon Chestov, philosophe du déracinement. La genèse de l'œuvre. Lausanne : Éditions l'Âge d'homme (Slavica), 2010, 451 p.

1 Parmi les philosophes russes du tournant $d u x^{e}$ siècle, Lev Šestov a sans doute une place à part. Son œuvre a suscité plus de controverses que nulle autre. De par son itinéraire délibérément solitaire, souvent à l'écart des problèmes et des préoccupations intellectuelles de son entourage, il s'est frayé un chemin de penseur autonome, extrême et péremptoire dans ses jugements, déconcertant dans ses opinions tant philosophiques que religieuses, allant fréquemment à l'encontre de ce qui est admis par le sens commun et la morale. En Russie, l'intérêt pour sa philosophie, redécouverte dans les années 1990, est en plein essor. C'est moins le cas en France. Malgré presque vingt ans de vie à Paris (il y est mort en 1938) et son amitié avec Boris de Schloezer, qui a traduit plusieurs de ses ouvrages en français, Šestov est très peu connu, surtout dans les milieux philosophiques. Pour une bonne introduction à sa pensée, on peut se reporter à l'un des rares ouvrages que nous possédions en langue française $L a$ philosophie du malheur d'Alexis Philonenko ${ }^{1}$, qui comporte un chapitre sur Šestov. Il manquait cependant une étude circonstanciée et systématique, présentant la vie et l'œuvre de Šestov dans leur intrication. L'ouvrage de Geneviève Piron vient combler cette lacune. Ouvrage consistant, issu d'une thèse de doctorat en littérature russe, il contient un examen minutieux de la genèse de la pensée existentielle de Šestov. L'originalité de l'approche de G. Piron tient dans le fait qu'elle cherche à donner une vision de cette œuvre à partir d'archives inédites (lettres, manuscrits, carnets, etc). Le caractère disparate des matériaux n'empêche pas que les mêmes questions éthiques ne cessent de se poser, quoique dans d'infinies variations. C'est pourquoi l'auteur opte 
pour un parcours, non pas chronologique, mais qu'on pourrait appeler « perspectiviste » - prenant chaque fois plusieurs vues sur un même problème.

Le livre prend son départ dans l'idée de déracinement qui figure déjà dans le titre. C'est également le nom de l'ouvrage le plus emblématique de Šestov, L'Apothéose du déracinement: essai de pensée adogmatique (1905) ${ }^{2}$. Ce thème revient constamment au fil des pages et la lecture de G. Piron en suit les traces tant dans la vie privée que dans l'œuvre de Šestov. Le déracinement est d'abord une expérience effectivement vécue par Šestov " une nuit de septembre 1895 » (p. 21), une "crise vécue comme révélation » (p.167) dont on ignore les circonstances, mais qui, selon les témoignages, a terriblement bouleversé Šestov. Mais c'est aussi plus généralement la vision du monde que Šestov élabore progressivement et, par conséquent, un prisme nécessaire pour la formation de sa méthode de lecture des textes philosophiques et littéraires.

L'ouvrage de G. Piron est composé de sept chapitres. Le premier restitue le contexte politique et culturel au tournant du siècle et la place de Šestov au sein de cette effervescence littéraire que connaît la Russie à l'époque de l'Âge d'argent. L'intrigue se joue autour de l'ambivalence de la personnalité de Šestov. Traité tour à tour de mystificateur, de provocateur, de prophète apostolique ou de sage juif, aucun de ces masques, comme le montre très bien l'auteur, ne suffit à le caractériser. Lui-même se nomme plus volontiers "l'homme du sous-sol», d'après le titre de la nouvelle de Dostoevskij. Le deuxième chapitre reprend quelques motifs déjà discutés dans le premier ; cependant il ne s'agit plus ici de faire jouer les «masques » de Šestov, mais d'entendre sa "voix», de suivre à partir de ses premiers textes, ses manuscrits et carnets de travail le commencement de son parcours intellectuel dans les années 1890. Šestov se fraie un chemin d'abord comme critique littéraire, en utilisant la littérature comme un moyen de s'adresser au peuple : il rêve alors d'engager une lutte politique à travers la littérature. Mais lors de la rédaction de son premier livre Shakespeare et son critique Brandes (1898), sa position change et il se produit ce que G. Piron nomme une " révolte éthique » (p.124). Dans les tragédies de Shakespeare, il découvre la conscience d'un profond désespoir, du sort tragique et du malheur humain, sans que l'on puisse y fournir une explication raisonnable. C'est le sujet, et son activité de réflexion, qui deviennent désormais le centre de la pensée chestovienne. Dans le troisième chapitre, G. Piron reprend en détail les principales étapes constituant le tournant intellectuel de Šestov en analysant de près Shakespeare et son critique Brandes. Ce livre est crucial, car on y voit à l'œuvre des transformations sur plusieurs plans. Šestov abandonne son idéalisme objectif (valeurs existant en soi) pour adopter une perspective «subjectiviste ». Dans le même sens, il passe d'une vision volontariste du monde à l'expression d'un sentiment de l'absurdité de l'existence frôlant le fatalisme. Sur le plan stylistique, cet ouvrage marque un changement dans l'écriture et l'introduction d'une expression fragmentaire et indirecte.

4 Dans le chapitre 4, G. Piron met en avant l'importance de l'expérience individuelle pour la pensée de Šestov. Lecteur assidu de Nietzsche, Kierkegaard, Pascal et Dostoevskij, Šestov veut toujours voir le cœur de leur œuvre dans un drame personnel réellement vécu. Cette sensibilité à l'expérience intérieure est liée, pour G. Piron, à la crise spirituelle que Šestov lui-même a subie. C'est pourquoi l'auteur entreprend de retracer minutieusement la vie de Šestov au moment de la crise. Dans le chapitre 5, G. Piron étudie ce qu'elle appelle l'herméneutique de Šestov. Elle montre que Šestov s'intéresse non pas au côté extérieur du livre, celui qui est exposé au public, mais toujours à sa face 
cachée, au « livre de la vie » que l'auteur analysé cherche inconsciemment à dissimuler. C'est pourquoi en lisant les textes de Dostoevskij, par exemple, Šestov est extrêmement attentif à la mise en scène de sa parole, à son éloquence, à ses notes hystériques qui trahissent un manque de confiance en soi, etc. Cette perspective quasi psychanalytique dans la lecture chestovienne pousse G. Piron à retourner en arrière, à relire à cette nouvelle lumière son texte sur Shakespeare et l'interprétation du personnage de Hamlet. Dans ses analyses de Nietzsche, Tolstoj et Dostoevskij, Šestov confronte deux « moi », « le juste » et le « juge » qui luttent éternellement dans leurs œuvres.

Le chapitre 6 est consacré à l'étude des " pérégrinations » chestoviennes à travers les âmes humaines, pérégrinations considérées par G. Piron comme "une méthode de recherche» (p. 233) élaborée par Šestov. Comment fonctionne l'hermeneutique chestovienne? C'est d'abord une mise en perspective historique, lorsqu'il tente d'interpréter à travers des personnages historiques qu'il extrait délibérément du temps et de l'histoire les problèmes les plus actuels. En confrontant de façon «kaléidoscopique» ses multiples personnages, il les fait dialoguer au moyen de citations, tirées çà et là de leurs œuvres. Toutefois, il aboutit toujours à un monologue, trouvant dans les textes qu'il lit une expérience sinon identique au moins semblable. De l'opposition des personnages il en vient à leur superposition, afin de rendre la contradiction qui anime la pensée de ses personnages, en dégage le sens caché.

Le dernier chapitre, intitulé La pensée comme acte et sous-titré "Chestov écrivain ", fournit une analyse rigoureuse et stimulante du style d'écriture pratiqué par le philosophe. La philosophie du déracinement requiert un autre type de langage qui ne serait pas un moyen de communication. La parole doit devenir " expression affective " (p. 299) et échapper à l'objectivation. Les procédés stylistiques changent et se diversifient avec le développement de la conception philosophique de Šestov. Pendant sa période idéaliste, Šestov estime que l'usage du langage ne peut être que poétique. Il joue sur ses côtés musicaux, purement expressifs, qui peuvent exprimer les subtilités de l'émotion humaine. Après la " crise ", il commence à privilégier le langage du double sens (allégorie). Il se fie aux premiers jets, à la spontanéité de la pensée, aux images. C'est là que peuvent se montrer sans se fixer, à ses yeux, une pensée ou intuition fortes, mais évanescentes. Le texte, par conséquent, ne peut pas être achevé, il se dissémine en fragments. Après 1902, la majorité des manuscrits se présentent sous forme aphoristique. Šestov pratique une pensée paradoxale mettant en scène des situations absurdes, recourant aux paraboles, impliquant l'emploi de l'ironie, de l'expression indirecte (apparenté en cela à Kierkegaard), mais aussi d'un humour noir qui vise à choquer, provoquer, surprendre. Tous ces procédés servent à mettre à l'écart le lecteur, à le "défamiliariser». Le style aphoristique de Šestov est comparable à celui de Nietzsche, mais comme le montre G. Piron, il emprunte son modèle stylistique plutôt à Lichtenberg.

7 Une étude vaste et riche sur l'œuvre de Šestov qui peut servir autant de belle introduction dans la pensée du philosophie que fournir aux spécialistes des perspectives innovantes. 


\section{NOTES}

1. A. Philonenko, La philosophie du malheur, P. : Vrin, 1998.

2. Traduction française : Léon Chestov, Sur les Confins de la vie: l'Apothéose du dépaysement, P. : Flammarion, 1967. 